\title{
An Approach to Deriving Surface Water Quality Criteria with Implications for Closure — Ranger Mine Case Study
}

\author{
D. Jones Supervising Scientist Division, Department of Environment and Heritage, Australia \\ C. Humphrey Supervising Scientist Division, Department of Environment and Heritage, Australia
}

M. Iles Supervising Scientist Division, Department of Environment and Heritage, Australia

R. van Dam Supervising Scientist Division, Department of Environment and Heritage, Australia

\section{$1 \quad$ INTRODUCTION AND PHYSICAL CONTEXT}

The numeric values specified for surface water quality closure criteria will strongly impact on the extent and nature of physical engineering works as well as the revegetation strategy needed to limit the total load of solutes and suspended sediments from a mine site. In the case of solute load this includes both direct surface water pathways and indirect delivery of solutes from the coupling of ground and surface water. Thus the setting of surface water quality criteria can, by default, also set a limit on permissible fluxes of solutes from such features as mine pits that have been backfilled with tailings. Hence surface water criteria are a vital requirement for successful closeout, and agreed criteria should be developed as early as possible in the closure planning process.

In this paper the application of the framework detailed in the Australian and New Zealand Guidelines for Fresh and Marine Water Quality (ANZECC and ARMCANZ, 2000) to the derivation of local water quality objectives for the operating life of a minesite will be described, and options proposed for extension of this framework to developing criteria for closure success and for assessing the trend through time of approach to conformance with these criteria.

The Ranger uranium mine, located approximately $250 \mathrm{~km}$ to the east of Darwin in Australia's Northern Territory, will be used a case study. The mining lease is surrounded by, but administratively distinct from, the World Heritage-listed Kakadu National Park (KNP). Production is scheduled to cease in 2014 according to the current life of mine plan. Following closure the requirement is for the disturbed areas to be rehabilitated to a condition consistent with the values of, and to be suitable for incorporation into, the Park.

In the case of water quality the following primary regulator-specified goals apply through operations and closure.

- Protect the health of Aboriginals and other members of the regional community.

- Maintain the health of the World-Heritage, Ramsar-listed Magela Creek wetlands downstream of the minesite.

- Maintain the natural biological diversity of the aquatic and terrestrial ecosystems of the Alligator Rivers Region.

The mine lies adjacent to Magela Creek which feeds the high conservation value Magela Creek wetlands (Figure 1). Consequently the water quality objectives for the operation are stringent, with the highest aquatic ecosystem protection level applied (defined in ANZECC and ARMCANZ, 2000).

The wet-dry tropical monsoonal climate is the key driver for water supply, with the $1500 \mathrm{~mm}$ average annual rainfall falling during the summer months between October and May, with essentially no rainfall for the rest of the year. The annual average evaporation is $2500 \mathrm{~mm}$. This cycling between "flood" and "drought" means that most of the feeder creek systems are ephemeral, introducing an additional level of complexity into defining water quality criteria. There are distinct natural annual variations in water quality between the initial 
flows at the start of the wet, the peak flow period during the middle of the wet, and the recessional flow period at the end of the wet.

The rainwater that feeds the Magela Creek system flows over an ancient weathered landscape, with the bulk of the upper catchment comprising sandstone plateau and escarpment. As a consequence, the baseline electrical conductivity of water in Magela Creek is extremely low, typically ranging from $10 \mu \mathrm{S} / \mathrm{cm}$ in the middle of the wet season to around $20 \mu \mathrm{S} / \mathrm{cm}$ at the beginning and end of the season. This means that low level inputs of major ion solutes that elsewhere would be trivial could, in this case, have a substantial impact on receiving water quality. Management of water coming from waste rock on the Ranger minesite during the wet season is, therefore, one of the most critical operational issues. Minimising solutes loads to Magela Creek will also be one of the greatest challenges for closure, when active water management will be replaced by passive systems.

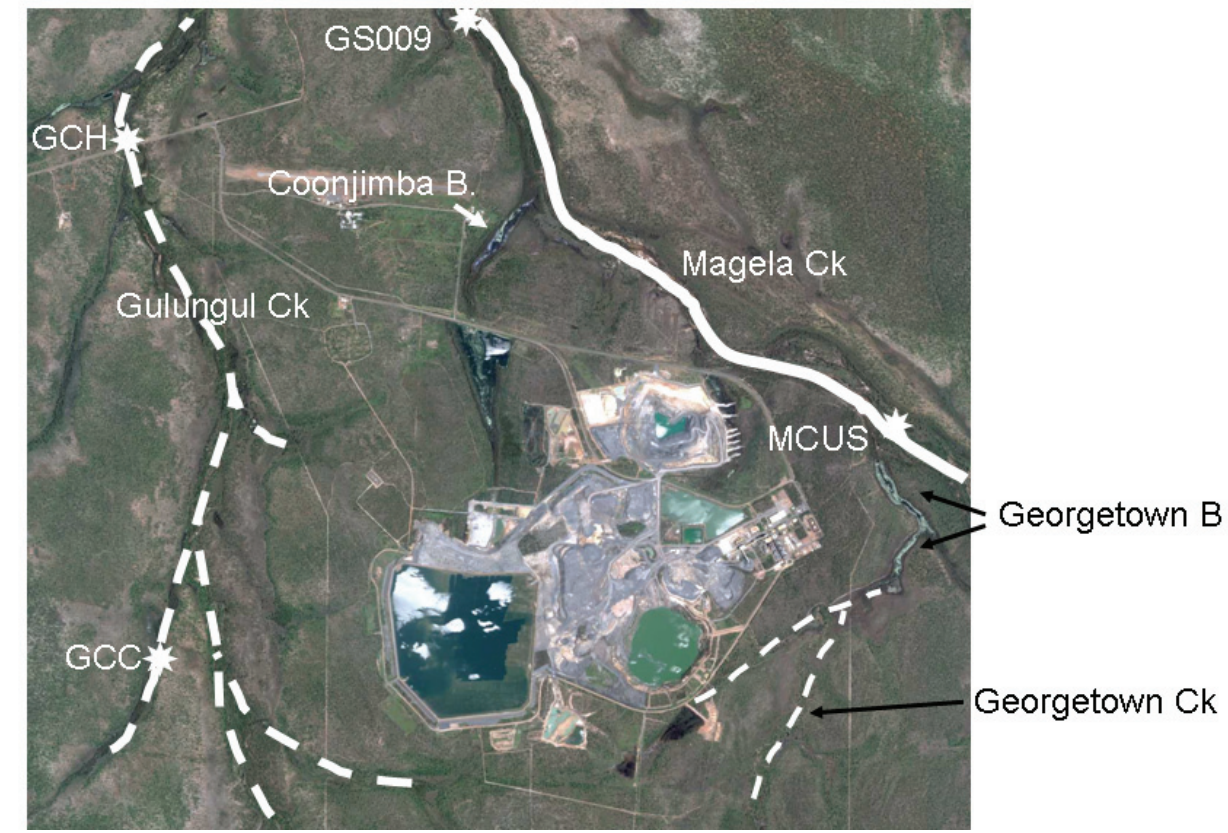
Figure $1 \quad$ Locations of catchment lines and natural waterbodies (billabongs - B) in relation to the Ranger mine. Upstream and downstream water sampling sites are indicated by

During the operational life of the mine the water quality compliance point is located at 'GS009' on Magela Creek downstream of the minesite (Figure 1). Contingent on outcomes of discussions with regulatory and traditional owner stakeholders, a more complex regulatory framework may be necessary post closure for key catchments - Magela Creek (receiving waterway), Gulungul and Corridor/Georgetown Creeks (mineinfluenced tributary catchments), and Georgetown and Coonjimba Billabongs (mine-impacted natural water bodies). Each of these aquatic systems will not only likely require different values for water quality criteria, but also different approaches to derive criteria to protect specific attributes.

\section{WATER QUALITY COMPLIANCE FRAMEWORK FOR PRIMARY RECEIVING WATERWAY (MAGELA CREEK)}

\subsection{Operational Life of Mine}

The ANZECC and ARMCANZ (2000) Water Quality Guidelines (hereafter the Guidelines) approach has been adopted to identify the dominant environmental values and level of protection required (a high 
conservation/ecological value aquatic ecosystem $)^{1}$ for waters downstream of the mine; determine background values of the important indictors (key variables) in Magela Creek adjacent to the mine (Iles, 2004); and, through an integrated monitoring and assessment program (Humphrey et al., 1999), identify and assess the ecological significance of changes in water quality. To provide a framework for assessing protection of the aquatic ecosystem and to aid precautionary and reactive management of mine site waters, a hierarchy of management or compliance trigger values for each key variable has been developed, based on local biological effects and local reference site data. Reporting and appropriate investigative/action responses have been prescribed for each trigger level (Iles, 2004).

This best practice approach represents one of the most comprehensive implementations of the ANZECC/ARMCANZ (2000) framework for deriving water quality values to protect a high conservation value aquatic ecosystem. A key tenet of the Guidelines philosophy is use, wherever possible, of biological response data in the derivation of water quality criteria, primarily because such information relates directly to management goals (couched in ecological terms) and because the values themselves are an integrated assessment or measure of (potential) contaminant effects (ANZECC and ARMCANZ, 2000). Of all the recommendations for applying the framework, two were fundamental to the approach adopted. They are:

- A high conservation value ecosystem should be managed so that, relative to a reference condition (i) the values of the indicators of biological diversity should not change, and (ii) there is no detectable change in the levels of chemical and physical stressors and toxicants - this latter condition can be relaxed where there is considerable local biological assessment data showing that such changes are not detrimental to the system.

- Guidelines for physical and chemical stressors and toxicants should be derived using, in order of preference, (1) local biological effects data, (2) local reference site data, or (3) default values provided in the Guidelines (based on regional reference data or global biological effects data).

These recommendations were adapted to establish a conservative process for setting water quality guidelines for Magela Creek, using the following hierarchical approach:

- Define maximum allowable (regulatory) limits for key variables using ecotoxicological data for local aquatic species.

- Produce management triggers from statistical distributions of water quality data at an appropriate (upstream) reference site.

- If triggers based on reference site data are inappropriate (for example, too conservative recognising that some level of impact on water quality is present), then findings from chemical and biological monitoring programs (if indicating that a higher than upstream baseline values can occur without significant detriment to ecosystem values) should be used to adjust the triggers.

On the other hand, the Aboriginal Traditional Owners of the area have indicated that they do not wish to see any change to the natural water quality. To reconcile these two positions, the system of having numerical values alone as water quality objectives was expanded. Narrative water quality objectives (see Table 1) were developed to be used in conjunction with numerical guideline values. This approach accommodates both the scientific objectives of robust data interpretation and ecosystem protection assessment, and the secondary management aim of minimising water quality changes downstream of the mine.

The numerical objectives form a hierarchy of values that trigger increasingly stringent management responses, and are known as 'focus' action' and 'guideline' or 'limit' trigger values. Focus, action and guideline triggers are derived from the statistical distribution of the local water quality record. Limits apply when the value is based on ecotoxicological testing and/or in-stream biological effects assessment data (uranium) or human dietary pathway modelling (radium).

\footnotetext{
${ }^{1}$ Apart from human health values, stakeholders also recognised 'cultural and spiritual values' as an environmental value to be protected. Strategies on how to define and protect this value are being developed by others and are not discussed in this paper.
} 
The process of applying the modified framework described above is developed in detail below for the case of Magela Creek to provide the basis for subsequent discussion of approaches to developing closure criteria.

\subsubsection{Triggers derived from ecotoxicological testwork}

\subsubsection{Uranium}

For uranium a high-reliability site-specific trigger value of $6 \mu \mathrm{g} / \mathrm{L}$ was determined using a species sensitivity distribution approach, recommended and described in the Guidelines (Hogan et al., 2003). This value should protect at least $99 \%$ of species in Magela Creek and has been adopted by the regulator as the compliance 'limit'.

Current downstream (GS009) uranium concentrations are elevated relative to the reference site (MCUS, Figure 1), although still more than an order of magnitude lower than the limit derived from ecotoxicological testing. This is a clear demonstration of a case where the use of trigger values derived from upstream reference site water quality statistics would have led to an overly conservative management framework.

The 'No Observed Effect Concentrations' (NOEC) ${ }^{2}$ from uranium toxicity tests ranged from 18 to $810 \mu \mathrm{g} / \mathrm{L}$ with a large confidence interval. The lower and upper 95\% CL's are 0.3 , and $103 \mu \mathrm{g} / \mathrm{L}$ respectively.

To capture this uncertainty in the management framework and enable uranium data to be interpreted in an environmental risk context, the lower 95 th $(0.3 \mu \mathrm{g} / \mathrm{L})$ and 80 th $(0.9 \mu \mathrm{g} / \mathrm{L})$ CLs of the ecotoxicity trigger value were adopted as the 'focus' and 'action' trigger values, respectively. These values are representative of concentrations that have occasionally been measured downstream but which biological monitoring has shown do not have detrimental effects on ecosystem health. They are thus conservatively protective of the environment, whilst being an appropriate management warning tool since they are only occasionally exceeded under normal operational circumstances.

Finally, narrative statements (Table 1) were coupled to these trigger values to address the secondary management aim for Magela Creek of minimising the extent of change from the upstream reference condition.

\subsubsection{Magnesium}

A similar process has recently been applied (van Dam et al., 2005; 2006) to assessing the toxicity of magnesium sulfate $\left(\mathrm{MgSO}_{4}\right)$, which, along with calcium $(\mathrm{Ca})$, is the dominant solute present in Ranger mine waters. The process of deriving the site-specific ecotoxicity-based limit was more complex in this instance because magnesium interacts very strongly in living systems with calcium. Therefore, the investigation had to identify the dominant toxic ion $(\mathrm{Mg})$, and assess both $\mathrm{Mg}$ toxicity and influences of $\mathrm{Ca}$ in the extremely soft and low ionic strength Magela Creek water.

Initial toxicity testing of six local species indicated that $\mathrm{MgSO}_{4}$ was more toxic than previously documented and that $\mathrm{Mg}$ was the toxic ion $\left(\mathrm{SO}_{4}\right.$ effects not observed below $200 \mathrm{mg} / \mathrm{L}$ and $\mathrm{MgCl}_{2}$ similarly toxic to $\mathrm{MgSO}_{4}$ according to mass of $\mathrm{Mg}$ ). Further investigations demonstrated that $\mathrm{Ca}$ had a marked ameliorating effect on $\mathrm{Mg}$ toxicity. By exposing the three most sensitive species to decreasing $\mathrm{Mg}$ :Ca ratios while maintaining a constant $\mathrm{Mg}$ concentration, a mass ratio of 9:1 $\mathrm{Mg}$ :Ca was found to completely ameliorate $\mathrm{Mg}$ toxicity to the hydra and duckweed. However, a $20 \%$ effect on snail reproduction remained at this and further decreasing ratios, suggesting the occurrence of an additional mechanism(s) of $\mathrm{Mg}$ toxicity unrelated to $\mathrm{Ca}$. The 9:1 Mg:Ca ratio was then tested at increasing $\mathrm{Mg}$ concentrations for all six species to determine the extent to which it would be protective of a range of taxa.

Preliminary results indicate a decrease in Mg toxicity of 2- to 200-fold, depending on the species, when calcium concentrations are increased to those typically found in Magela Creek water downstream of the

\footnotetext{
${ }^{2}$ The No-Observed-Effect-Concentration (NOEC) is the highest test concentration at which the test organism response is not statistically different to that of unexposed (ie. contol) organisms, and for which all higher test concentrations do produce a statistically significant response by the test organisms (typically at a statistical alpha level of 0.05). The NOEC is used as an estimate of an 'acceptable' or 'safe' concentration for a species.
} 
minesite. The Mg concentration for $99 \%$ species protection thus increases to around $4 \mathrm{mg} / \mathrm{L}$ based on these latest findings.

Derivation of appropriate trigger values in this instance require consideration of both the magnesium concentration and the $\mathrm{Mg}: \mathrm{Ca}$ ratio. For example, a protocol such as that suggested below might be able to be established by agreement with the regulator.

- If the Mg:Ca ratio is less than 9:1, then the magnesium concentration at GS009 in Magela Creek must be less than $4 \mathrm{mg} / \mathrm{L}$ following mixing with solute inputs from the minesite.

- If the Mg:Ca ratio is greater than 9:1, then the magnesium concentration must be less than $1.2 \mathrm{mg} / \mathrm{L}$.

This work on the toxicity of $\mathrm{Mg}$ and the protective effect of $\mathrm{Ca}$ may have significant implications for the many mine sites where $\mathrm{Mg}$ is the dominant major cation in site runoff.

\subsubsection{Trigger values derived from upstream reference condition}

For $\mathrm{pH}, \mathrm{EC}$, turbidity, manganese, magnesium and sulfate 80th, 95th and 99.7th percentiles were calculated from 10 years (1993-2003) of upstream reference site data. For pH, low values are also of relevance so 20th, 5 th, and 0.3 rd percentiles were also calculated. These percentiles are distribution independent nearequivalents of one, two and three standard deviations around a mean, respectively, and represent the three smallest steps of change statistically detectable.

The reference site percentiles were displayed as control chart thresholds on a times series chart of historic downstream data (for example, Figure 3) to determine how often the downstream data exceeded the percentiles. If the percentiles are exceeded with the frequency statistically expected $(20,5$ and $0.7 \%$ for the three respective percentiles), then water quality at the downstream site can be considered unchanged from reference conditions, and the reference percentiles provide conservative guidelines for identifying any change from background values. In such cases the 80th, 95th and 99.7th (and the 20th, 5th and 0.3rd for $\mathrm{pH}$ ) percentiles were adopted as the 'focus', 'action' and 'guideline' trigger values. Exceedances of these triggers at the downstream compliance point trigger precautionary or remedial management actions. The greater the extent of exceedance the greater the level of management action required.

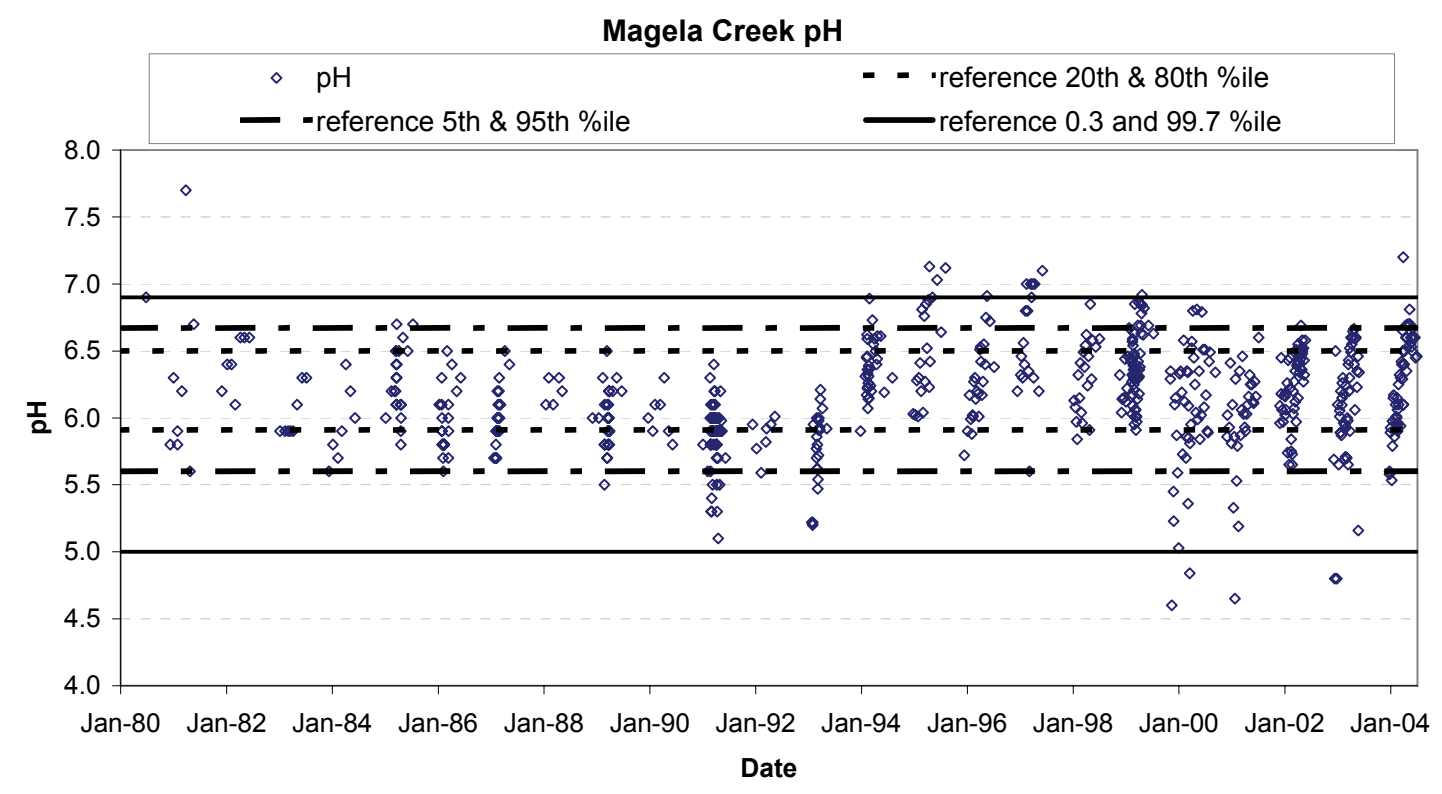

\section{Figure 2 Historic downstream pH points overlaid with trigger percentiles derived from upstream reference site}

It is recognised that the current trigger values for turbidity are not of high reliability (and too conservative) given that they are based on weekly grab samples collected at times that do not coincide with peak storm- 
induced flow. This is a generic deficiency with the grab sampling monitoring regime that is used at many mine sites. During high flow conditions concentrations of sediment typically increase, whereas most other variables decrease. Sediment loads are also usually higher at the start of a wet season (Evans et al., 2004) and continuous sediment concentration-discharge data obtained in another small local creek indicate that suspended mud can move through a stream system in pulses or waves associated with rainfall-generated discharge events (Evans et al., 2003).

To address this identified deficiency in the turbidity criteria, continuous turbidity measuring equipment was installed at MCUS and GS009 at the start of the last wet season. These data will be analysed in conjunction with the corresponding continuous flow record and will be used to produce turbidity guideline criteria that better reflect stream flow dynamics.

\subsubsection{Refining trigger values using an adaptive management approach}

The approach described here represents a form of "adaptive management" whereby the initially most conservative position of no statistical change in water quality from the upstream reference condition in Magela Creek has been, with the agreement of all stakeholders, relaxed as more specific local knowledge was acquired about response of the local aquatic ecosystem to low level mining-related inputs.

Trigger values (based on percentiles as above) for variables (magnesium, sulfate and EC) that were already elevated at the downstream site (GS009), relative to the upstream reference site (MCUS), were derived from the distribution of data at a slightly-modified site located about $300 \mathrm{~m}$ downstream of MCUS. This approach is regarded as being sufficiently protective, yet not overly conservative, since measurements of fish and macroinvertebrate abundance and diversity at this location indicated that the change in water quality had not caused any significant impact. It represents the application of an adaptive approach to the derivation of management triggers using the opportunity presented by current site conditions. Narrative statements were coupled to the trigger values to address the secondary management aim of minimising future change in Magela Creek.

Examples of water quality objectives produced by each of the three approaches detailed above, together with the associated narrative descriptions, are provided in Table 1.

Table 1 Water quality objectives for Magela Creek (2006)

\begin{tabular}{|l|l|l|l|}
\hline Parameter & Method & Objective & Trigger values \\
\hline $\mathrm{pH}$ & $\begin{array}{l}\text { Upstream } \\
\text { reference site }\end{array}$ & $\begin{array}{l}\text { To retain the natural distribution of } \mathrm{pH} \text { in } \\
\text { Magela Creek and report and act on any trigger } \\
\text { value exceedances. }\end{array}$ & $\begin{array}{l}\text { Focus: } 5.9 \text { and } 6.5 \\
\text { Action : } 5.6 \text { and } 6.7 \\
\text { Guideline: } 5.0 \text { and } 6.9\end{array}$ \\
\hline EC & $\begin{array}{l}\text { Adaptive } \\
\text { modified } \\
\text { upstream site }\end{array}$ & $\begin{array}{l}\text { To (i) report and act on any exceedances of the } \\
\text { focus, action and guideline trigger values, and } \\
\text { (ii) to sustain the improved water quality seen in } \\
\text { the last two wet seasons when practical. }\end{array}$ & $\begin{array}{l}\text { Focus: } 21 \mu \mathrm{S} / \mathrm{cm} \\
\text { Action: } 30 \mu \mathrm{S} / \mathrm{cm} \\
\text { Guideline: } 43 \mu \mathrm{S} / \mathrm{cm}\end{array}$ \\
\hline Uranium & Ecotoxicology & $\begin{array}{l}\text { To (i) report and act on any trigger value } \\
\text { exceedances, and (ii) to sustain the lower } \\
\text { uranium concentrations measured in the last two } \\
\text { wet seasons when practicable. }\end{array}$ & $\begin{array}{l}\text { Focus: } 0.3 \mu \mathrm{g} / \mathrm{L} \\
\text { Action: } 0.9 \mu \mathrm{g} / \mathrm{L} \\
\text { Limit: } 6 \mu \mathrm{g} / \mathrm{L}\end{array}$ \\
\hline
\end{tabular}




\subsection{Decommissioning and Closure}

\subsubsection{Developing and specifying closure guidelines}

Arguably the distribution of water quality data measured at the downstream compliance point during the operational life of the mine provides a benchmark for closure. Whilst this assertion may initially appear to be controversial it does receive strong support from both the laboratory ecotoxicological testwork and from the long record of macroinvertebrate and fish abundance and diversity data available for Magela Creek downstream of GS009. In this context it must also be recognised that return to pre-mining baseline conditions at GS009 is not likely to occur in the intermediate to medium term given the time required for the newly created landform to come to weathering equilibrium and the low, but finite inputs from groundwater that will occur over the intermediate to long term.

The key issue here is to locate the "optimum" position between the most conservative endpoint of NIL detectable downstream perturbation above background, and the maximum extent of perturbation above the upstream reference condition that can occur without compromising achievement of the primary environmental protection objectives. The framework developed above for compliance assessment during the operational life of the mine provides a robust technical basis from which to argue the relative merits of various options for specifying water quality closure criteria. However, the final basis for specifying such criteria are yet to be debated and agreed by all stakeholders involved in the closure planning process.

\subsubsection{Post closure monitoring and performance assessment}

It is likely that the trigger value framework developed for monitoring and assessing water quality in Magela Creek during the operational life of the mine can be applied, with some modification, to post closure performance assessment.

Nevertheless, there is the question of what will represent final "success" in the context of demonstrating the level of compliance required for ultimate signoff with the regulator. While it could be argued that the frequency of exceedance of the focus and action triggers for the range of water quality parameters should be lower following closure than during the operational life of the mine, during and immediately following decommissioning of the site the frequency of exceedance may well increase, before declining again, as the rehabilitated footprint evolves to a long-term steady state condition. Thus the closure agreement reached with stakeholders needs to accommodate this possibility. Notwithstanding this short term relaxation of frequency of exceedance of management triggers, peak values of parameters should at all times remain below the upper guideline or limit value.

In the intermediate to longer term a trend towards convergence with the downstream focus values established during the operational period of the mine might provide a reasonable indicator that closure has been successful with respect to water quality parameters. As discussed above this approach would accommodate a finite level of input of solutes from the site whilst maintaining a sufficiently conservative level of protection for the downstream aquatic environment.

\section{WATER QUALITY COMPLIANCE FRAMEWORK FOR MINE IMPACTED CREEK POST CLOSURE (GULUNGUL CREEK)}

It might appear that Gulungul Creek is similar to Magela Creek in that upstream and downstream (of mine impact) locations (see GCC and GCH on Figure 1) could be compared and used to derive water quality guidelines. However, one of the problems with small catchments in general is that upstream (closer to source) water quality can often be poorer than downstream quality. This occurs as a result of the higher surface area to volume ratio at these locations, and also a result of local differences in geochemistry in headwater subcatchments. This is a generic problem and illustrates the care required in the design and interpretation of results from water quality monitoring programs for mine sites located near the headwaters of potentially affected catchments.

Turbidity is very different from the other stressors because of a common condition in small catchments where upstream values are higher than downstream values. Data collected over several years in Ngarradj 
Creek (a small catchment in the ARR) show that the "reference" site upstream of the Jabiluka project area has a higher sediment load, and therefore higher turbidity, than the site downstream of the potentially affected area (Evans et al., 2004). This is expected in a small catchment according to the sediment delivery ratio theory (Walling, 1983) where under similar disturbance conditions, larger area catchments generally have lower sediment concentrations than smaller area catchments. Under these circumstances upstream reference conditions do not provide a good guideline against which increases in sediment concentration at the downstream site can be assessed.

One way to overcome this is to base trigger values on the distribution of a baseline dataset of difference values (for example, Evans et al., 2004). Upstream and downstream sites are treated as paired sites and the comparison of differences between the pairs is used to assess impact, with measured differences being compared against percentiles of baseline differences. Continuous turbidity measuring equipment was installed in Gulungul Creek prior to the start of the 2004/05 wet season and this will be used to provide over several years the data needed to test the application of the difference approach described above.

To address the problem of the upstream site not being an appropriate reference for the downstream site it is proposed that a similar approach be used for physicochemical parameters (apart from turbidity) as for Magela Creek. That is, the downstream water quality record is used in conjunction with biological monitoring data from the stream to derive water quality triggers that will be sufficiently conservative to flag the need for management action in advance of detrimental impact on the aquatic ecosystem. Thus a "control chart" approach will be developed whereby any sustained trends away from required behaviour can be identified. The provision will exist for future revision of the trigger values as more water quality and biological data are acquired in future years.

\section{$4 \quad$ NATURAL WATERBODIES POST CLOSURE}

\subsection{Overview}

When the Ranger mine ceases operations the requirement is for the disturbed areas to be rehabilitated to a condition consistent with the values of Kakadu National Park (KNP), and to be suitable for reincorporation back into the Park. In the case of natural waterbodies this would mean that their post rehabilitation environmental beneficial use values should be consistent with the expectations of the traditional owners of the land. This could be interpreted to mean that the visual aesthetic and hunter-gatherer potential of the waterbody and its surrounds are consistent with similar unimpacted habitats of KNP. Georgetown Billabong (GTB) is the largest and arguably the most important such waterbody located in close proximity to the current operational area (Figure 1). The approach used to derive closure criteria for GTB provides a model for other natural waterbodies on the lease.

The physical surrounds of GTB and its coupling with water flows from the surrounding catchment (Magela and Georgetown Creeks) has remained largely unchanged on an annual basis since mining began. Consequently the terrestrial landscape immediately surrounding the billabong is not of significant concern.

The key concern is the potential for delivery of solutes from the rehabilitated mine landform post closure. These solutes, if present at too high a loading, could impact on water quality and hence on the biological integrity of the waterbody. The principal objective of the closure planning process will be to produce a design for the current disturbed area such that the delivery of solutes and suspended sediment from the disturbed footprint in the catchment of Corridor and Georgetown Creeks will not compromise the post closure beneficial use objectives for the waterbody.

Use of both pre-mining baseline and upstream reference site data to derive water quality criteria is problematic because of the lack of relevant baseline and upstream sites, and because the waterbody has historically been impacted by low level discharges from the mine. However, monthly water quality data are available from GTB while intermittent water quality, fish and macroinvertebrate data are available both from GTB and from reference sites (billabongs in the region un-impacted by mining) that may be used for comparison.

The situation is additionally complicated by a bi-phasic seasonal regime, with flushing of the billabong occurring during the wet season. This flushing ceases at the end of the wet, with the billabongs contracting in 
surface area and undergoing substantial evaporative concentration during the six months of the subsequent dry season (Figure 3).

Thus two sets of water quality criteria are required - one for the wet season and one for the dry season - to avoid application of inappropriately conservative criteria during the dry. An approach to deriving the wet season criteria using a combination of water quality and macroinvertebrate community structure time series data, and the derivation of dry season quality criteria from end of dry season maxima (that is, worst water quality) is described below.

\subsection{Derivation of Water Quality Criteria from Biological Indicators}

The general philosophy and recommendation of deriving water quality criteria from local biological response data (sensu ANZECC and ARMCANZ, 2000) are being applied to the setting of water quality closure criteria for GTB. For example, if the post-closure condition in GTB is to be consistent with similar undisturbed (reference) billabong environments of KNP, then the range of water quality data from the billabong over time that supports such an ecological condition in GTB (as measured by suitable surrogate, biological indicators) may be used for this purpose.

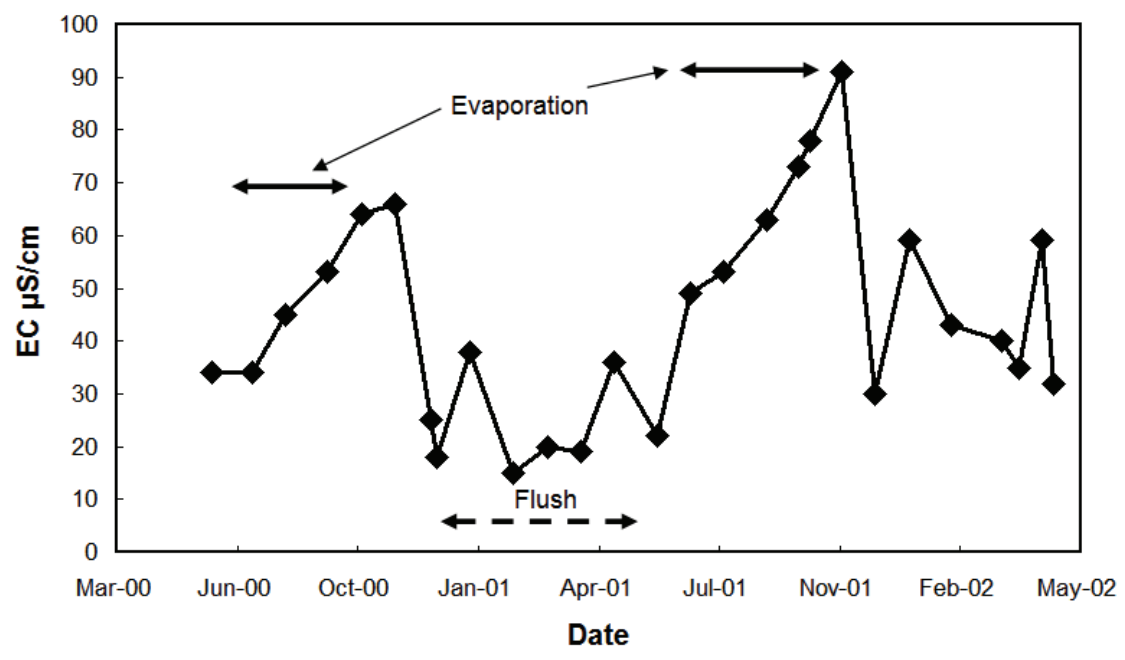

Figure 3 Annual cycle of electrical conductivity in Georgetown Billabong. Wet season typically starts in November and ends in May

Potential biological indicators that have been measured in GTB include fish and macroinvertebrate communities. While data for both community groups have been measured intermittently since 1979, it has only been since the mid 1990s that standardised monitoring or surveying of these communities has been in place. The fish monitoring record since 1994 is more or less uninterrupted, though comparable macroinvertebrate data have only been collected in 1995 and 1996 (with sampling also having been recently completed in June 2006). While the fish record is more complete, macroinvertebrate data are regarded as more useful for setting water quality criteria because of the enhanced sensitivity of this group of organisms to water quality generally (eg ANZECC and ARMCANZ, 2000), including the local Alligator Rivers Region (ARR) (Faith et al., 1995; Stowar et al., 1997). Henceforth we discuss the application of macroinvertebrate data from water bodies in the ARR towards derivation of water quality closure criteria in GTB.

Macroinvertebrates were collected from the littoral zones of ARR billabongs in the early dry season (May), when diversity and abundances are high after wet season flooding, from 7 (1995) and 11 (1996) lentic water bodies. Four of these water bodies in each year were exposed to mine waste waters to varying extents, including GTB, while the remainder served as reference water bodies. In 1995, altered, if not impaired, macroinvertebrate community structure was observed in three 'mine-exposed' water bodies (O'Connor et al., 1996) while in 1996 effects were less obvious, a factor attributed (O'Connor et al., 1997) to less rainfall in 1996 and, subsequently, to reduced volumes of waste water generated from the Ranger mine and dispersed to the mine-exposed receiving' water bodies. 
In both 1995 and 1996, the community structure of macroinvertebrates in GTB resembled that of other reference water bodies (O'Connor et al., 1996, 1997). As stated above, this undisturbed condition could potentially be maintained into the future by taking as water quality criteria those physicochemical data that supported this (undisturbed) ecological condition.

Macroinvertebrate communities of shallow lowland billabongs of the ARR, such as GTB, are seasonally dynamic. Species diversity, abundance and biomass reach maxima in the early dry season, then decline dramatically, in association with reduced food availability and water quality, over the dry season to minima in December (Marchant, 1982; Outridge, 1988). In Marchant's (1982) 1979 and Outridge's (1988) 1981 sampling seasons, a maximum 46 and 45 "species" ${ }^{3}$ from the littoral zone of GTB were recorded in the early dry season, falling sharply to 13 and 8 species respectively by December. Thus, the late dry season taxa richness represented only $28 \%$ and $18 \%$, respectively, of the original species assemblages recorded by Marchant and Outridge. This is not to say that all missing species have become extinct from the billabong: a number of species are still present in numbers too small to be represented in samples and/or may take refuge as aestivating stages in the billabong sediments (eg Paltridge et al 1997). A large number of aquatic insect species from such billabongs, however, take flight as adults over the dry season. Subsequent recruitment in the following wet season is either through deposited egg masses from aerial stages, or from drift from inflowing creek waters following wet season re-wetting and filling of the billabong.

The consequence of the seasonal recruitment patterns and annual 're-setting' of a large number of macroinvertebrate species in lowland billabongs as described above is that populations from these species may be short-term transients in the billabong, lacking a capacity to pre-adapt to long-term changes in water quality and other environmental conditions in the billabong. Thus while a 'healthy' macroinvertebrate community present in the early dry season of a particular year would reflect the water quality of the preceding wet season, and indeed to some (unknown) extent, water quality of the antecedent dry season, it does not necessarily reflect water quality for time spans greater than this.

Thus, the conservative approach adopted in this paper is to base post-closure water quality objectives for GTB (consistent with other undisturbed environments of KNP) on the range of water quality data from the billabong over the preceding wet season (wet season criteria) and dry season (dry season criteria). In practice, this entails for the two sampling years, 1995 and 1996, setting wet season criteria on the basis of water quality measured over the period January to May of both years, and dry season criteria on the basis of the worst water quality observed in the preceding dry seasons, typically for the months September to December. Median and 80th percentile values for 3 key water quality variables relevant to Ranger, electrical conductivity (EC), magnesium and uranium, representing summary statistics from which water quality closure criteria may be derived, have been calculated from the combined water quality records from the two sampling years (1995 and 1996). These statistics are shown in Table 2, and compared for reference with the statistics derived from the entire $27 \mathrm{y}$ water quality record since mining started in the catchment.

Using the advice contained in ANZECC and ARMCANZ (2000) for the derivation of water quality 'trigger values' - closure criteria for this study, exceedance of which may elicit management action - are typically based upon the 80th percentile of the reference data (derived separately for wet and dry seasons, Table 2).

From Table 2, it can be seen that the values of wet season criteria derived from 1995 and 1996 data, are lower than equivalent values derived from all years, whilst dry season values derived for 1995 and 1996 are greater than equivalent values derived from the entire water quality dataset. The reliability of $\mathrm{Mg}$ values for the 1995 and 1996 wet seasons may be questioned given the sparse data available (Table 2). However, for any time period selected for the $27 \mathrm{y}$ record of wet season water quality data (all data, 1980s, 1990s, 2000s) there is a significant regression relationship between EC and $\mathrm{Mg}$. The regression equation derived for the EC-Mg data from the 1990s (not shown here) predicts, from the more numerous EC data available for 1995 and 1996 (Table 2), Mg values of 1.4 (median) and 1.7 (80th percentile) $\mathrm{mg} / \mathrm{L}$. These are essentially the same values as derived from the much smaller available $\mathrm{Mg}$ data sets for these two years.

\footnotetext{
${ }^{3}$ Substantial taxonomic changes to the macroinvertebrate fauna of the ARR have taken place since these early studies and hence the original species lists derived at that time are either inaccurate or have been revised.
} 
An extensive macroinvertebrate sampling round conducted in May 2006 will provide an additional year of matched macroinvertebrate and water quality data. Once the final data are to hand they will be merged with the 1995 and 1996 datasets and the water quality values presented in Table 2 recalculated. It is anticipated that macroinvertebrate sampling will be repeated several more times between now and projected mine closure in 2014 and the guideline values adjusted, if required, to incorporate this new information.

\section{Table 2 Median and 80th percentile values for major mine-related water quality indicators measured monthly in Georgetown Billabong}

\begin{tabular}{|c|c|c|c|c|c|}
\hline $\begin{array}{l}\text { Water quality } \\
\text { variable }\end{array}$ & & $\begin{array}{l}\text { Wet season } \\
\text { values - } \\
1995 \& 1996\end{array}$ & $\begin{array}{l}\text { Wet season } \\
\text { values - } \\
\text { all years }\end{array}$ & $\begin{array}{l}\text { Dry season } \\
\text { values - } \\
1995 \text { \& } 1996\end{array}$ & $\begin{array}{l}\text { Dry season } \\
\text { values - } \\
\text { all years }\end{array}$ \\
\hline \multirow[t]{3}{*}{$\mathrm{EC}(\mu \mathrm{S} / \mathrm{cm})$} & $\mathrm{N}$ & 15 & 265 & 9 & 110 \\
\hline & Median & 27 & 32.1 & 88.7 & 65.5 \\
\hline & 80th percentile & 36 & 44.4 & 136 & 92.2 \\
\hline \multirow[t]{3}{*}{$\mathrm{Mg}(\mathrm{mg} / \mathrm{L})$} & $\mathrm{N}$ & 4 & 176 & 4 & 64 \\
\hline & Median & 1.3 & 1.9 & 2.1 & 2.1 \\
\hline & 80th percentile & 1.7 & 2.7 & 2.6 & 3.1 \\
\hline \multirow[t]{3}{*}{$\mathrm{U}(\mu \mathrm{g} / \mathrm{L})$} & $\mathrm{N}$ & 17 & 262 & 10 & 108 \\
\hline & Median & 0.35 & 0.51 & 1.2 & 0.48 \\
\hline & 80th percentile & 0.43 & 1.38 & 1.9 & 1.24 \\
\hline
\end{tabular}

\section{$5 \quad$ CONCLUSIONS}

The Ranger Mine has been used as a case study to illustrate how biological indicators and ecotoxicological testwork can be combined with a water quality record from downstream of a minesite to derive water quality guideline values that are not as conservative as would be produced by the default approach of conformance with the upstream reference condition. This approach has been further adapted to tributary streams and to onsite natural waterbodies.

It has been argued that the trigger value framework developed for performance monitoring of water quality in Magela Creek during the operational life of the mine can be applied, with some modification, to post closure performance assessment. This approach would accommodate an ongoing finite level of input of solutes from the site whilst maintaining a sufficiently conservative level of protection for the downstream aquatic environment.

Biological and water quality data have also been used to develop a technically defensible framework for deriving post closure water quality guidelines for an on site natural waterbody that has historically received low levels of inputs from the minesite. 


\section{REFERENCES}

ANZECC and ARMCANZ (2000) Australian and New Zealand guidelines for fresh and marine water quality. National Water Quality Management Strategy Paper No 4. Australian and New Zealand Environment and Conservation Council \& Agriculture and Resource Management Council of Australia and New Zealand, Canberra.

Evans, K.G., Moliere, D.R., Saynor, M.J., Erskine, W.D. and Bellio, M.G. (2003) Assessing the impact of catchment disturbance on mud transport in a seasonal stream. In proceedings of the National Environment Conference, Brisbane, Institution of Engineers Australia 18-20 June 2003.

Evans, K.G., Moliere, D.R., Saynor, M.J., Erskine, W.D. and Bellio, M.G. (2004) Baseline suspended-sediment, solute, EC and turbidity characteristics for the Ngarradj catchment, Northern Territory, and the impact of mine construction. Supervising Scientist Report 179, Supervising Scientist, Darwin NT.

Faith, D.P., Dostine, P.L. and Humphrey, C.L. (1995) Detection of mining impacts on aquatic macroinvertebrate communities: Results of a disturbance experiment and the design of a multivariate BACIP monitoring programme at Coronation Hill, Northern Territory, Australian Journal of Ecology, 20, pp. 167-180.

Humphrey, C.L., Thurtell, L., Pidgeon, R., van Dam, R. and Finlayson, M. (1999) A model for assessing the health of Kakadu's streams, Australian Biologist, 12, pp. 33-42.

Iles, M. (2004) Water quality objectives for Magela Creek - revised November 2004. Internal Report 489, December, Supervising Scientist, Darwin. Unpublished paper.

Kuffler, S.W., Nichols, J.G. and Martin, A.R. (1984) From neuron to brain: a cellular approach to the function of the nervous system. Second Edition. Sinauer Associated Inc. Publishers, Massachusetts, USA.

Marchant, R. (1982a) The macroinvertebrates of Magela Creek, Northern Territory. Research report 1, Supervising Scientist for the Alligator Rivers Region, AGPS, Canberra.

O’Connor, R., Humphrey, C.L. and Lynch, C. (1997) Macroinvertebrate community structure in Magela Creek between 1988 and 1996: Preliminary analysis of monitoring data. Internal report 261, Supervising Scientist, Canberra. Unpublished paper.

O’Connor, R., Humphrey, C.L., Dostine, P., Lynch, C. and Spiers, A. (1996) A survey of aquatic macroinvertebrates in lentic waterbodies of Magela and Nourlangie Creek catchments, Alligator Rivers Region, NT. Internal report 225, Supervising Scientist, Canberra. Unpublished paper.

Outridge, P.M. (1988) Seasonal and spatial variations in benthic macroinvertebrate communities of Magela Creek, Northern Territory, Australian Journal of Marine and Freshwater Research, 39, pp. 211-23.

Paltridge, R.M., Dostine, P.L., Humphrey, C.L. and Boulton, A.J. (1997) Macroinvertebrate recolonization after rewetting of a tropical seasonally-flowing stream (Magela Creek, Northern Territory, Australia), Australian Journal of Marine and Freshwater Research, 48, pp. 633-645.

Stowar, M., Pidgeon, B., Humphrey, C.L. and Boyden, J. (1997) Effects of suspended solids on stream biota downstream of a road crossing on Jim Jim Creek, Kakadu National Park: Final report. Internal report 244, Supervising Scientist, Canberra.

van Dam, R., Hogan, A., McCullough, C., Humphrey, C.L., Nou, S. and Douglas, M. (2006) Influence of calcium on the ecotoxicity of magnesium: Implications for water quality trigger values. In ERISS research summary 20042005. K.G. Evans, J. Rovis-Hermann, A. Webb \& D.R. Jones, Supervising Scientist Report 189, Supervising Scientist, Darwin NT, pp. 15-19.

van Dam, R., McCullough, C., Hogan, A., Humphrey, C.L., Nou, S. and Douglas, M. (2005) How toxic is magnesium sulfate? Implications for the mining industry. Australasian Society for Ecotoxicology, 2005 Conference, 25-28 April, Melbourne, Australia.

Walling, D.E. (1983) The sediment delivery problem, Journal of Hydrology, 65, pp. 209-237. 